\title{
Selection of a Plant-Bacterium Pair as a Novel Tool for Rhizostimulation of Polycyclic Aromatic Hydrocarbon-Degrading Bacteria
}

\author{
Irene Kuiper, Guido V. Bloemberg, and Ben J. J. Lugtenberg \\ Leiden University, Institute of Molecular Plant Sciences, Wassenaarseweg 64, 2333 AL Leiden, \\ The Netherlands \\ Submitted 21 February 2001; Accepted 8 June 2001.
}

We developed a novel procedure for the selection of a microbe-plant pair for the stable and efficient degradation of naphthalene. Based on the rationale that root exudate is the best nutrient source available in soil, the grass (Lolium multiflorum) cultivar Barmultra was selected because of its abilities to produce a highly branched root system, root deeply, and carry a high population of Pseudomonas spp. bacteria on its roots. Starting with a mixture of total rhizobacteria from grass-like vegetation collected from a heavily polluted site and selecting for stable naphthalene degradation as well as for efficient root colonization, Pseudomonas putida strain PCL1444 was isolated. The strain's ability to degrade naphthalene was shown to be stable in the rhizosphere. Moreover, it had superior root-colonizing properties because, after the inoculation of grass seedlings, it appeared to colonize the root tip up to $\mathbf{1 0 0}$-fold better than the efficient root colonizer Pseudomonas fluorescens WCS365. Strain PCL1444 uses root exudate as the dominant nutrient source because the presence of grass seedlings in soil results in up to a 10-fold increase of PCL1444 cells. Moreover, the root colonized by strain PCL1444 was able to penetrate through an agar layer, resulting in the degradation of naphthalene underneath this layer. In addition, the inoculation of grass seeds or seedlings with PCL1444 protected them against naphthalene phytotoxicity. Finally, this plant-microbe combination appeared able to degrade naphthalene from soil that was heavily polluted with a complex mixture of polycyclic aromatic hydrocarbons. To our knowledge, this is the first time that a naturally occurring bacterium has been selected for the combination of the abilities to degrade a pollutant and colonize plant roots. We suggest that the principle described here, to select a bacterium which combines efficient root colonization with a beneficial activity, also can be used to improve the selection of other more efficient plant-bacterium pairs for beneficial purposes such as biocontrol, biofertilization, and phytostimulation.

Additional keyword: bioremediation.

The contamination of soil and groundwater with polycyclic aromatic hydrocarbons (PAHs) is a widespread environmental

Corresponding author: B. J. J. Lugtenberg; Fax: +31 71527 5088; Telephone: +31 71527 5065; E-mail: lugtenberg@ rulbim.leidenuniv.nl problem. It is the result of incomplete fossil fuel combustion, leakage from storage tanks, oil spills, and various industrial processes (Leahy and Colwell 1990; Long 1993; Morgan and Watkinson 1989). Mechanical injection of contaminated sites with pollutant-degrading bacteria has been used to clean polluted sites in an inexpensive and less labor-intensive way than the removal and/or combustion of polluted soils (Cerniglia 1993; Grosser et al. 1991; Timmis and Pieper 1999). Degradation by the injected bacteria, however, is limited for a number of reasons. First, high beneficial bacterial population numbers cannot be maintained, presumably because of low nutrient availability and low energy yield from the degradation of the polluting compounds (Cerniglia 1993; Goldstein et al. 1985; Leahy and Colwell 1990; Ramadan et al. 1990). The addition of nutrients can increase bacterial activity, but this method is expensive and too labor-intensive for larger contaminated sites. Second, injected microbes cannot penetrate less porous layers and do not reach the deeper layers of the soil, and third, the plasmids that usually encode the ability to degrade pollutants can be lost in soil.

In this paper, we describe a novel method to select a plantbacterium pair to increase the efficiency of biodegradation of PAHs. The use of plants as bio-injectors of pollutant-degrading bacteria has a number of advantages such as a highly branched, deep root system that can be used as a vector for the more-or-less homogeneous bio-injection of root-colonizing bacteria and for the penetration of layers normally not permeable to bacteria. Additionally, because roots can exude up to $35 \%$ of their photosynthate as exudate carbon (Gregory and Atwell 1991; Keith et al. 1986; Lynch and Whipps 1990; Trofymow et al. 1987) and release oxygen or provide better redox conditions (Bodelier et al. 2000; King 1994), which can become limiting for bacterial growth in soil, the rhizosphere is a good environment for bacteria to survive and proliferate (Anderson et al. 1993; Aprill and Sims 1990; Brazil et al. 1995; Hiltner 1904; Liste and Alexander 2000; Nichols et al. 1997; Schwab et al. 1995; Walton and Anderson 1990; Yee et al. 1998). It also has been shown that upon the inoculation of seeds and seedlings with bacteria, certain strains can proliferate excellently on the root (Dekkers et al. 1998; Schippers et al. 1995) and colonize the root tip (Simons et al. 1996). Lastly, root systems take up large amounts of the surrounding water, thereby bringing the dissolved pollutants into the rhizosphere (Erickson 1997).

Grass is an attractive candidate because grass cultivars exist in which the root system is highly branched and can root 
deeply. In addition, the monocots wheat and grass can carry approximately 10 -fold more bacteria on the root system, especially on the lower parts, compared with the dicots cucumber, tomato, potato, and radish (I. Kuiper, unpublished results). When the inoculant microbe also is able to colonize efficiently and degrade one or more pollutants, we expect that the resulting plant-microbe combination is much more efficient in soil remediation than is the mechanical injection of microbes.

High concentrations of pollutants can prevent almost all vegetation. The rhizospheres of the plants that are able to grow under such conditions can be rich in pollutant-degrading bacteria. For instance, the first plants that appeared in oil-polluted fields after the Gulf War had a rhizophere rich in oil-degrading microorganisms (Radwan et al. 1995). We used this observation in our selection strategy.

For reasons mentioned above, grass was chosen as the model plant and naphthalene as the model PAH.

\section{RESULTS}

\section{Selection of a grass cultivar for bioremediation.}

The criteria for the selection of the most suitable grass cultivar were the ability to germinate and grow in the presence of naphthalene, the ability to root deeply, and a root system with a high capacity to carry bacteria. Seven cultivars were selected initially by Barenbrug Research (Wolfheze, The Netherlands), a major grass seed firm, on the basis of their knowl- edge that these cultivars have extensive root systems. None of the cultivars appeared to be affected in germination and growth by the presence of naphthalene when tested in PAH-polluted soil, which is a sandy soil that contains naphthalene, phenanthrene, fluoranthrene, antracene, benzo(a)-fluoranthrene, and chrysene. These substances were present at 34, 26, 16, 4.7, 4.3 , and $3.4 \mathrm{mg}$ per $\mathrm{kg}$ of soil, respectively, whereas trace amounts of other PAHs brought the total amount of PAHs to approximately $100 \mathrm{mg}$ per $\mathrm{kg}$ of soil. In addition, the cultivars were not affected in growth and germination when tested in quartz sand-naphthalene and in potting soil-naphthalene compared with growth in the absence of naphthalene in quartz sand-plant nutrient solution (PNS) and in potting soil.

After 12 days of growth in PAH-polluted soil, the root systems of three cultivars, Lolium perenne cv. Barpolo, Lolium multiflorum cv. Barmultra, and L. perenne cv. Bardessa, were superior in root length and branching compared with those of the others. After visual inspection of the three cultivars, Barmultra appeared to develop the longest $(15.6 \pm 1.7 \mathrm{~cm})$ and most branched (data not shown) roots compared with Barpolo and Bardessa, which developed root systems of $12.4 \pm 1.5$ and $11.0 \pm 1.2 \mathrm{~cm}$ in length, respectively. The ability to carry the highest number of the three selected root colonizing Pseudomonas spp. bacteria was determined in three different experiments after 8 days of plant growth in the quartz sand-PNS gnotobiotic system. The total number of colony forming units (CFUs) of Pseudomonas fluorescens WCS365, P. fluorescens

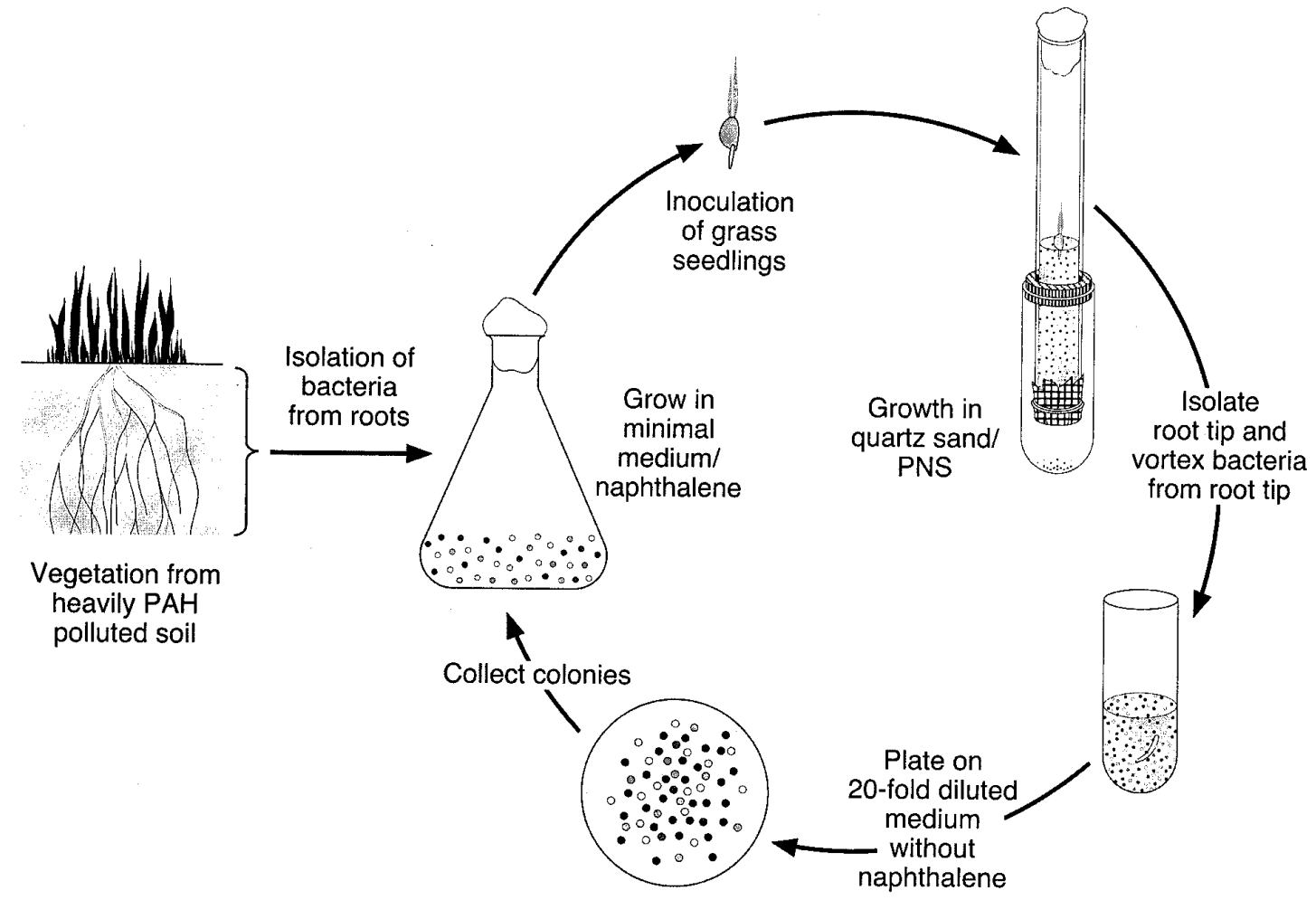

Fig. 1. Selection of a root colonizing, naphthalene-degrading bacterium. Bacteria were isolated from the root system of a grass-like plant from polycyclic aromatic hydrocarbon (PAH)-polluted soil. Bacteria were isolated on 20-fold diluted tryptic soy agar medium, subsequently grown in standard naphthalene medium, and finally selected for excellent root tip colonization on grass (Lolium multiflorum) cultivar Barmultra in the gnotobiotic system. This procedure was repeated twice. 
R2f, and Pseudomonas putida WCS358 on the total root systems, depicted as $\log _{10}(\mathrm{CFU}+1) \pm$ standard deviation, were $6.1 \pm 0.52,6.4 \pm 0.06$, and $6.7 \pm 0.22$ for Bardessa; $6.7 \pm 0.25$, $6.6 \pm 0.26$, and $7.0 \pm 0.26$ for Barmultra; and $6.1 \pm 0.40,6.2 \pm$ 0.70 , and $6.5 \pm 0.20$ for Barpolo; respectively. Because the root system of Barmultra has the longest and most branched root system as well as the ability to carry the highest number of bacteria, it was selected as the most suitable plant.

\section{Enrichment procedure for an efficient,} root-colonizing, naphthalene-degrading bacterium.

The criteria chosen for the selection of a suitable bacterium were the ability to grow at a high rate on an inexpensive growth medium to make production of the inoculant economically feasible, a stably maintained ability to quickly degrade naphthalene, and the ability to efficiently colonize the root system of Barmultra after seedling inoculation. To this end, a grass-like plant was picked from a PAH-polluted site located in The Netherlands. After removal of the bulk soil, roots and adhering soil were used as a source for enrichment of putative naphthalene-degrading, root colonizing bacteria with the use of a novel selection procedure (Fig. 1). After growth on 20fold diluted tryptic soy agar (TSA) (Martin 1974), followed by growth in minimal medium containing naphthalene as the sole carbon source (standard naphthalene medium [SNM]), the resulting suspension, after dilution to $10^{8} \mathrm{CFU} / \mathrm{ml}$, was used to inoculate Barmultra seedlings. Those bacteria that were able to colonize the root tip after 7 days of plant growth were isolated and subjected to two more selection cycles for stable growth on naphthalene and root tip colonization (Fig. 1). The numbers of different colony types on the TSA plates, after the first, second, and third enrichment cycles, were larger than 50, at least 10, and six, respectively. Finally, this procedure resulted in six different isolates. After individual screening of these strains for growth in pure culture in liquid SNM, only one isolate, which we named PCL1444, appeared able to grow. The other strains were not able to grow in pure culture in liquid SNM and seemed dependent upon the presence of PCL1444 for growth on naphthalene.

\section{Characterization of isolate PCL1444.}

Nucleotide sequencing of the $1.5-\mathrm{kb} 16 \mathrm{~S}$ ribosomal DNA fragment, obtained by colony polymerase chain reaction (PCR), and comparison with the DNA databases revealed that the closest homology (98\%) was with the 16S ribosomal DNA of $P$. putida strain MnB1. The naphthalene-degrading ability of strain PCL1444 appeared stable because it was maintained completely after presence on the plant root for 8 days or growth in liquid King's medium B (KB) (King et al. 1954), without naphthalene, for approximately 100 generations. Generation times of PCL1444 in liquid KB, standard succinate medium (SSM) (Meyer and Abdallah 1978), and SNM were determined to be 33, 57, and $65 \mathrm{~min}$, respectively.

To measure the degradation rate of naphthalene by a low inoculum of strain PCL1444 in liquid SNM, the naphthalene concentration was determined during PCL1444 growth. The results of two different experiments (Fig. 2) show a decrease in naphthalene concentration directly after inoculation, with a rate of approximately $2 \mu \mathrm{g}$ per h per $10^{5} \mathrm{CFU}$ during the first $8 \mathrm{~h}$. When samples were taken after $16 \mathrm{~h}$, no naphthalene could be detected and approximately $10^{6} \mathrm{CFU} / \mathrm{ml}$ of PCL1444 bacteria were present. When growth of PCL1444 on naphthalene as the sole carbon source was compared with that of the well-known naphthalene degrader P. fluorescens strain 5R (King et al.

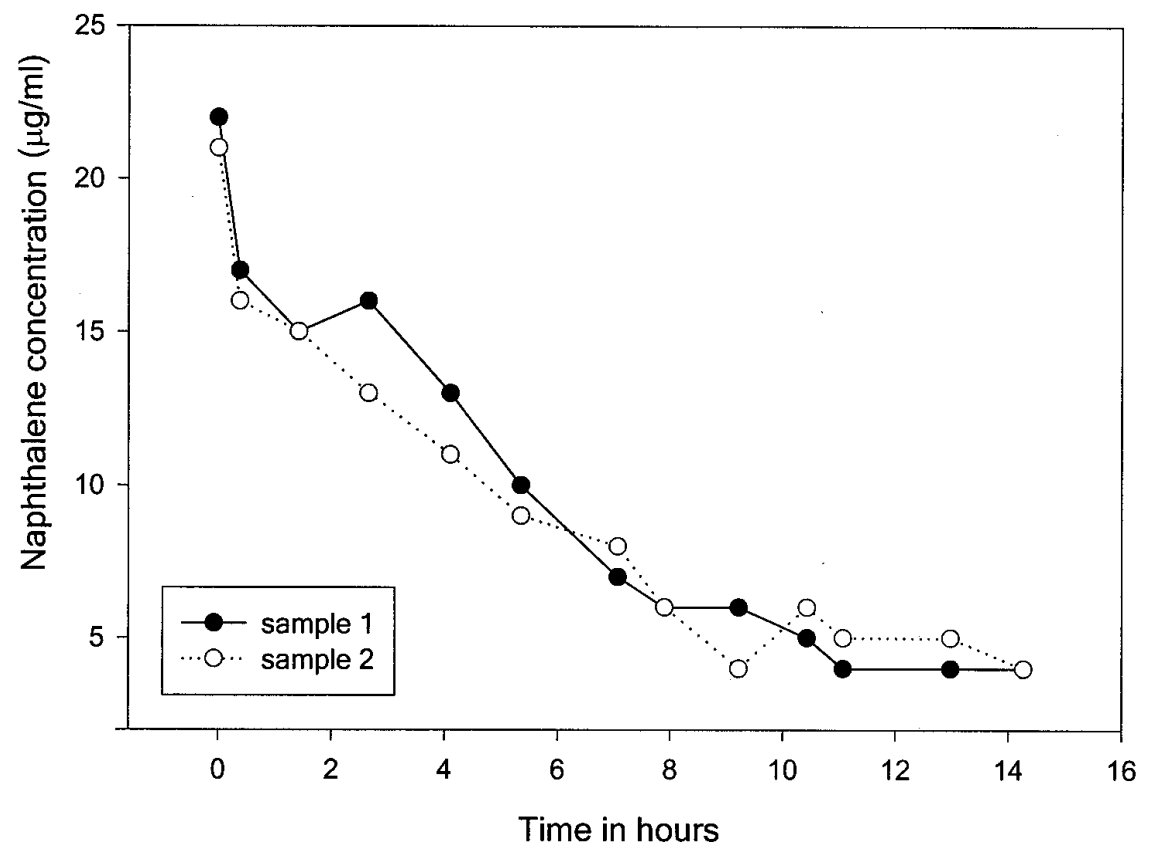

Fig. 2. Naphthalene degradation of PCL1444 in standard naphthalene medium (SNM). The medium was inoculated with cells from a stationary phase culture of strain PCL1444 in SNM to a concentration of $10^{5} \mathrm{CFU} / \mathrm{ml}$. Duplicate samples were collected after various time periods and extracted with 2 volumes of hexane. Gas liquid chromatography was used to measure the naphthalene concentration of the hexane fraction. Detection limit was $1 \mu \mathrm{g}$ per ml of naphthalene. 
1990), results showed that strain PCL1444 grows approximately 1.5 times faster (data not shown).

The grass root colonizing ability of isolate PCL1444 was compared with that of the very efficient root colonizing $P$. fluorescens strain WCS365 after seedling inoculation with a 1:1 mixture of PCL1444 and the lacZ-marked WCS365 derivative PCL1500 in the gnotobiotic quartz sand-PNS system or the quartz sand-naphthalene system. Root tip colonization of PCL1444 was approximately 10- and 100-fold better in the absence and presence, respectively, of naphthalene than that of PCL1500 (Fig. 3). Because no influence of the presence of naphthalene on grass root colonization by $P$. fluorescens strain WCS365 in the gnotobiotic quartz sand-PNS system was observed (data not shown), the increase in the number of PCL1444 bacteria on the root tips in the quartz sand-naphthalene system must be the result of the presence of naphthalene. Consequently, PCL1444 also is able to utilize naphthalene in the rhizosphere.

A rifampin-resistant derivative, which did not differ from wild-type strain PCL1444 with respect to growth rate and root tip colonization ability in the quartz sand-PNS system, was selected. We used the rifampin-resistant PCL1444 derivative to test whether this strain was able to compete with the indigenous microbial population and whether the plant could have a

\section{A}
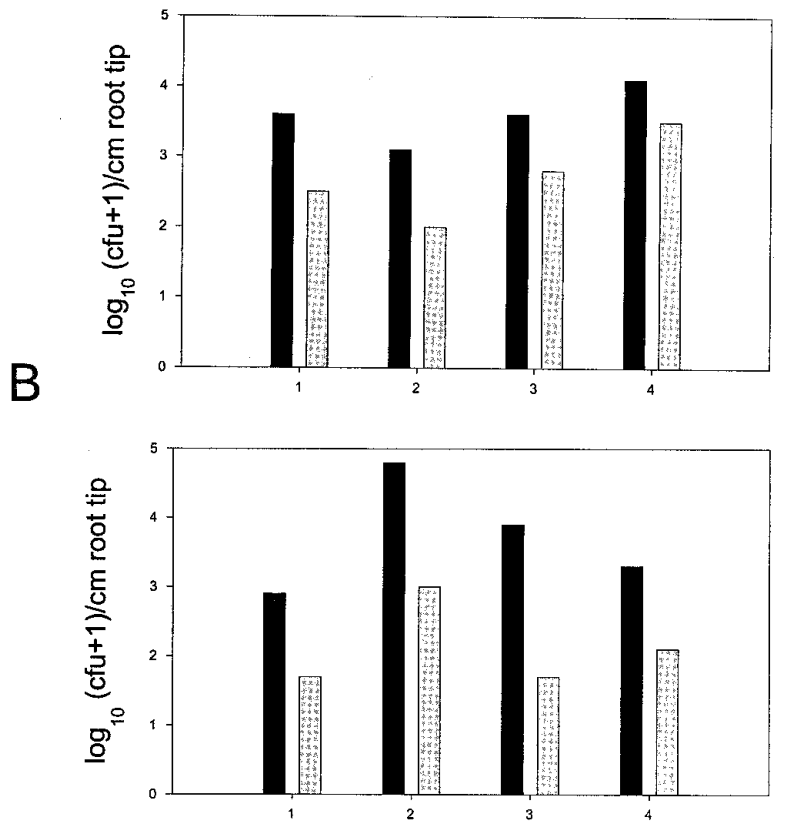

Fig. 3. Competitive grass root tip colonization between isolate PCL1444 (black bars) and the excellent colonizer Pseudomonas fluorescens WCS365 (gray bars). After the inoculation of grass seedlings (Lolium multiflorum cv. Barmultra) with a 1:1 mixture of strains PCL1444 and the lacZ-marked WCS365 derivative PCL1500, plantlets were grown for 7 days in the gnotobiotic system with A, quartz sand-plant nutrient solution and $\mathbf{B}$, quartz sand-naphthalene. Bacteria were isolated from the root tip, and dilutions were plated on King's medium B (King et al. 1954) containing X-Gal, which blue stains PCL1500 colonies. Each bar represents the average result of 10 plants. In all four independent experiments (1-4), the difference between the two strains is significant, according to the Wilcoxon-Mann-Whitney test. positive influence on the number of bacteria. Results obtained after 8 days (Table 1) show that approximately 10-fold higher bacterial numbers of strain PCL1444 were present in tubes with plants in which roots were present throughout the whole tube compared with tubes without plants. After 16 days of incubation in potting soil, the numbers of PCL1444 after seedling inoculation were approximately 100 -fold higher than after injection without plants (7.6/0.6 and 5.8/0.35 $\log _{10} \mathrm{CFU}$ per tube, respectively). Plating samples on KB plates, without antibiotics, showed that the bacterial background in potting soil and PAH-polluted soil was approximately $10^{7}$ and $10^{9} \mathrm{CFU} / \mathrm{g}$, respectively.

\section{Characterization}

of naphthalene degradation mutant PCL1454.

Transposon mutagenesis, followed by selection for the lost ability to grow on SNM, yielded mutant PCL1454. Isolation of chromosomal DNA of PCL1454, digestion with EcoRI, and subsequent recirculation of DNA yielded plasmid pMP5406. Sequence analysis of the chromosomal insert showed that the Tn5-luxAB is inserted in a DNA region between two open reading frames (ORFs). The $280 \mathrm{bp}$ of the ORF upstream of the transposon insertion showed $94 \%$ homology on an amino acid level with the $\operatorname{dox} G$ homolog of Pseudomonas spp. (Denome et al. 1993), and $280 \mathrm{bp}$ of the ORF downstream of the transposon insertion showed $98 \%$ homology on an amino acid level with the $d o x H$ homolog (Denome et al. 1993). The spacing between the transposon and the stop codon of the dox $G$ homolog and the start codon of the $\operatorname{doxH}$ homolog is 90 and $280 \mathrm{bp}$, respectively.

PCL1444 protects grass against naphthalene toxicity.

Grass plants inoculated with strain PCL1444 were growing normally (aboveground green parts approximately $6 \mathrm{~cm}$ in length) in the closed system where tubes were sealed with Viton stoppers (Rubber, Hilversum, The Netherlands), and $3 \mathrm{mg}$ of naphthalene was mixed through $15 \mathrm{~g}$ of sand. Uninoculated seedlings or seedlings inoculated with the naphthalene degradation-deficient mutant PCL1454, however, were not able to grow when naphthalene was present in the system (no aboveground structures were detected). Growth of uninoculated seedlings or seedlings inoculated with PCL1444 or PCL1454 bacteria was normal in the absence of naphthalene, resulting in aboveground green parts approximately $6 \mathrm{~cm}$ in length.

After 5 days of plant growth, naphthalene was extracted from the sand from tubes containing seedlings inoculated with approximately $10^{6}$ CFUs of PCL1444 bacteria and tubes in which uninoculated seedlings were planted. In the first case,

Table 1. Survival and proliferation of PCL1444-rifampin cells in the rhizosphere of Barmultra grass plants grown in different soil types ${ }^{\mathrm{a}}$

\begin{tabular}{lcc}
\hline & \multicolumn{2}{c}{$\log _{\mathbf{1 0}}(\mathbf{C F U}+\mathbf{1}) /$ tube \pm standard deviation } \\
\cline { 2 - 3 } Soil type & Without plants & With plants \\
\hline Potting soil & $4.8 \pm 0.50$ & $6.1 \pm 0.11$ \\
Potting soil- & $5.3 \pm 0.23$ & $6.3 \pm 0.17$ \\
naphthalene & & $5.9 \pm 0.22$ \\
\hline PAH-polluted soil & $4.4 \pm 0.07$ & .
\end{tabular}

a The number of PCL1444-rifampin bacteria in the soil per tube, after inoculation on seedlings or after injection of the corresponding number of bacteria into the soil, was determined after 8 days of incubation. Results are the mean of 10 tubes in each experiment. 
the naphthalene concentration was 100 -fold decreased (approximately $0.03 \mathrm{mg}$ of naphthalene per tube), whereas no decrease in naphthalene concentration was observed in the tubes without PCL1444 bacteria where plants could not grow (approximately $2.7 \mathrm{mg}$ of naphthalene per tube).

\section{Roots can function as a bioinjection system for cells of the colonizing and naphthalene-degrading strain PCL1444.}

To test whether Barmultra grass roots are able to act as a vehicle for bacteria to penetrate through an agar layer that is impermeable to bacteria, inoculated and control grass plants were grown in a two-layer system (see below) consisting of tubes containing $3 \mathrm{mg}$ of naphthalene in the lower sand layer and no naphthalene in the upper sand layer. In control tubes without plants and/or bacteria, approximately $2.5 \mathrm{mg}$ of naphthalene was left in the sand after 8 days, indicating that approximately $0.5 \mathrm{mg}$ had evaporated during the preparation and incubation of the plant tubes (Table 2). Roots sometimes reached the naphthalene-containing layer on day 6 , but usually this occurred on day 7. When naphthalene was extracted from the sand before the roots reached the naphthalene-containing layer, no decrease in the naphthalene concentration was observed (up to day 5; data not shown). As soon as the roots of seedlings inoculated with strain PCL1444 had penetrated the agar layer and reached the naphthalene-containing sand, however, naphthalene degradation occurred rapidly. After 7 days, a decrease in naphthalene concentration could be observed clearly (Table 2), whereas after 8 days, when plant roots inoculated with strain PCL1444 had been present in the naphthalene-containing sand for approximately 1 or 2 days, only $0.05 \mathrm{mg}$ of naphthalene was left (Table 2). When bacteria of strain PCL1444 were inoculated in the sand without plants but in the same cell numbers as present on two seedlings, no degradation of naphthalene was observed. When control seedlings without bacteria or seedlings inoculated with the naphthalene degradation-defective mutant PCL1454 were grown for 7 or 8 days, no significant decrease in naphthalene concentration after extraction of the sand from the tubes was observed (Table 2).

Also in reconstituted naphthalene-polluted soil (see below), the combination of Barmultra grass inoculated with PCL1444 resulted in the highest decrease in naphthalene content. After 8 days, the concentration of naphthalene in tubes only with soil, with sterile plants, and with plants inoculated with PCL1444 was $1.3 \pm 0.2,1.2 \pm 0.2$, and $0.7 \pm 0.2 \mathrm{mg}$ per tube, respectively.

\section{DISCUSSION}

The experiments described were designed to select a plantmicrobe pair for the efficient degradation of naphthalene. Barmultra was selected because its root system is the longest and most branched of the seven tested cultivars and has the ability to carry the highest number of the three tested Pseudomonas species after seedling inoculation.

Subsequently, we selected bacteria from the rhizosphere of a grass-like plant from the rare vegetation of a site heavily polluted with PAHs. We used a novel enrichment procedure (Fig. 1) to select for bacteria, fulfilling carefully identified selection criteria. First, we plated a suspension of bacteria isolated from the rhizosphere of the grass-like plant on 20-fold diluted TSA medium to assure that the isolates were able to grow in an inexpensive medium, which is an important cost advantage for the commercial production of bacterial inoculant. Then we grew these bacteria as a mixture on a medium with naphthalene as the sole carbon source to select for strains that were able to rapidly degrade naphthalene, subsequently applying the resulting mixture on seedlings and selecting for those isolates that efficiently reach the growing root tip, in order to make sure that the resulting isolates were excellent root colonizers.

Indeed, strain PCL1444, identified as $P$. putida, appeared to grow almost as fast on naphthalene as the sole carbon source as it did on succinate, the standard carbon source for pseudomonads. Moreover, a comparison of the growth rates on naphthalene of isolate $P$. putida PCL1444 with that of $P$. fluorescens 5R, a well-characterized naphthalene degrader (King et al. 1990), showed that strain PCL1444 grows approximately 1.5 times faster.

We compared the root-colonizing ability of isolate PCL1444 with that of $P$. fluorescens WCS365, which has been chosen for colonization studies (Lugtenberg et al. 1999) because it was the best competitive root colonizer of a series of strains used for the biocontrol of phytopathogenic fungi (Simons et al. 1996). It appeared that, after seedling inoculation, P. putida PCL1444 is a superior colonizer of Barmultra (Fig. 3) because it is approximately 10-fold better than WCS365 in the absence of naphthalene and 100-fold better than WCS365 in the presence of naphthalene. Because we have been testing competitive root colonization of bacterial strains on monocotyledons plants for many years and never found a better colonizer than WCS365, we attribute the superior grass root tip colonizing ability of $P$. putida strain PCL1444 to the enrichment procedure. In an approach to directly isolate naphthalene-degrading strains from the rhizosphere of the same plant source, we isolated 26 naphthalene-degrading strains, from which only nine appeared to be stable in this ability, and none were better root colonizers than WCS365 (data not shown). In addition, when competitive root tip colonization between PCL1444 and the monocot isolate P. fluorescens strain OE 28.3 (de Mot and Vanderleyden 1991) was tested, the number of CFUs of strain

Table 2. Grass roots as bioinjection system for Pseudomonas putida PCL1444 bacteria

\begin{tabular}{lcc}
\hline & \multicolumn{2}{c}{ Naphthalene per tube $^{\mathrm{a}} \mathbf{\text { I SD }} \mathbf{S D}^{\mathbf{b}}(\mathbf{m g})$} \\
\cline { 2 - 3 } Treatment $^{\mathbf{c}}$ & $\mathbf{7}$ days & $\mathbf{8 ~ d a y s}$ \\
\hline Sterile plants & $2.6 / 0.2$ & $2.3 / 0.1$ \\
Plants + PCL1444 & $1.7 / 0.4$ & $0.05 / 0.04$ \\
Sterile sand & $2.6 / 0.4$ & $2.3 / 0.01$ \\
Plants + PCL1454 & $2.3 / 0.3$ & $2.4 / 0.02$ \\
PCL1444 without plants & $2.6 / 0.5$ & $2.3 / 0.09$ \\
\hline
\end{tabular}

${ }^{a}$ Numbers represent the average amount of naphthalene that was left in eight independent tubes containing sterile plants, plants inoculated with strain PCL1444, sand without plants and bacteria, plants inoculated with mutant PCL1454, and no plants, although PCL1444 bacteria were injected on the same position where seedlings would have been planted, respectively.

${ }^{\mathrm{b}} \mathrm{SD}$ : standard deviation.

${ }^{c}$ Seedlings, sterile or inoculated with wild-type strain PCL1444 or its naphthalene degradation-defective mutant PCL1454, were grown for 7 and 8 days in plant tubes of a two-layer system, with $3 \mathrm{mg}$ of naphthalene mixed through the sand of the lower layer. The tubes were extracted with hexane, and gas liquid chromatography was used to analyze samples of the hexane fractions. 
OE 28.3 on the root tips was beneath the detection limit (data not shown). This novel procedure therefore offers great opportunities to select naturally occurring strains that combine beneficial traits such as biofertilization, phytostimulation, and biocontrol with a strong root colonization ability.

After 8 days of inoculation in polluted and unpolluted soils that contained approximately $10^{9}$ and $10^{7} \mathrm{CFUs}$, respectively, of indigenous bacteria per $\mathrm{g}$ of soil, it appeared that strain PCL1444 is an excellent competitor of the indigenous microflora because high numbers were maintained. The presence of the plant resulted in an approximately 10 -fold increase in bacteria of the inoculant strain (Table 1). After 16 days in potting soil, the number of PCL1444 bacteria was 100-fold higher than in the tubes inoculated with bacteria but not containing plants. These results indicate that the presence of the plant results in a strongly increased survival as well as the proliferation of PCL1444 bacteria, presumably mainly by the utilization of root exudate.

Experiments in which naphthalene degradation in the twolayer system was measured in polluted soil (see above) indicate that a significant fraction of the naphthalene is degraded, even without the addition of plants or PCL1444 bacteria. This is most likely the result of indigenous naphthalene-degrading bacteria. The degradation of naphthalene was enhanced substantially by the presence of Barmultra plants inoculated with P. putida strain PCL1444, whereas the presence of uninoculated plants had no significant effect (see above). These results provide opportunities for the application of the selected plantbacterium pair for cleaning polluted soils.

When the naphthalene concentration in the atmosphere is high, as it is in the closed system, Barmultra plants die unless they have been inoculated with PCL1444 bacteria. This results in a decrease of the naphthalene content in the sand. Apparently, inoculation with naphthalene-degrading bacterium protects the plant against naphthalene toxicity. The principle be- hind this finding can be used on polluted soil where vegetation is hardly possible. By selecting a suitable plant-bacterium pair, inoculated seeds or seedlings can be used as pioneer plants to grow on such soils and degrade the pollutants.

The results (Table 2) show that plant roots can penetrate an agar layer, which cannot be penetrated by bacteria alone. After seedlings inoculated with the excellent root colonizer PCL1444 were used, we observed that naphthalene present in the lower layer is efficiently degraded. Two interpretations are possible. First, the roots act as a carrier to deliver bacteria across an impermeable layer. Second, the plant makes holes in the agar layer, through which naphthalene from the lower layer reaches the upper layer where it is degraded by the bacteria present there. The following experiment supports the first interpretation. When PCL1444 was replaced by a mutant impaired in naphthalene degradation but that converts naphthalene to a pigmented product, this product was observed mainly in the lower compartment of the two-layer system (data not shown). This result presents the possibility that the plant root is able to deliver bacteria to compartments that normally cannot be reached such as clay clumps containing pollutants.

The proposed combination of beneficial traits and the ability to colonize the root system in a bioinoculant opens doors to a more effective use of such bioinoculants.

\section{MATERIALS AND METHODS}

\section{Bacterial strains and growth conditions.}

The bacterial strains described in this study are listed in Table 3. All Pseudomonas spp. strains were cultured at $28^{\circ} \mathrm{C}$ in liquid $\mathrm{KB}$, under vigorous shaking. Escherichia coli strains were grown in liquid Luria-Bertani medium (Sambrook et al. 1989), under vigorous shaking.

Media were solidified with $1.8 \%$ Bacto agar (Difco Laboratories, Detroit, MI, U.S.A.) and, when appropriate, supple-

Table 3. Bacterial strains

\begin{tabular}{|c|c|c|}
\hline Strain designation & Relevant characteristics & Reference or source \\
\hline \multicolumn{3}{|l|}{ Pseudomonas spp. } \\
\hline WCS358 & $\begin{array}{l}\text { P. putida; able to utilize a wide range of different } \\
\text { siderophore- } \mathrm{Fe}^{3+} \text { complexes. }\end{array}$ & Geels and Schippers 1983; Koster et al. 1993 \\
\hline WCS365 & $\begin{array}{l}\text { Wild-type } P \text {. fluorescens; isolated from potato roots, } \\
\text { which is a very efficient root colonizer of various } \\
\text { plants. }\end{array}$ & Dekkers et al. 1998; Geels and Schippers 1983; Simons et al. 1996 \\
\hline $5 \mathrm{R}$ & $\begin{array}{l}\text { P. fluorescens wild type; able to degrade naphthalene, } \\
\text { isolated from a manufactured gas plant soil. }\end{array}$ & King et al. 1990 \\
\hline$R 2 f$ & $\begin{array}{l}\text { P. fluorescens wild type; used in grass rhizosphere } \\
\text { studies. }\end{array}$ & Van Elsas et al. 1988 \\
\hline PCL1444 & $\begin{array}{l}\text { Wild-type } P \text {. putida; isolated from the rhizosphere of a } \\
\text { grass-like plant grown in polycyclic aromatic } \\
\text { hydrocarbons-polluted soil. }\end{array}$ & This study \\
\hline PCL1454 & $\begin{array}{l}\text { Tn5-luxAB derivative of strain PCL1444 impaired in } \\
\text { naphthalene degradation. }\end{array}$ & This study \\
\hline PCL1500 & $\begin{array}{l}\text { Tn } 5 \text {-lacZ marked derivative of WCS365, which colonizes } \\
\text { roots as efficiently as WCS } 365 \text {. }\end{array}$ & van der Bij et al. 1996 \\
\hline \multicolumn{3}{|l|}{ Escherichia coli } \\
\hline DH5 $\alpha$ & $\begin{array}{l}\text { endAl gyrSA96 } \mathrm{hrdR} 17(\mathrm{rK}-\mathrm{mK}-) \text { supE44 recAl; } \\
\text { general-purpose host strain used for transformation and } \\
\text { propagation of plasmids, }\end{array}$ & Boyer and Roulland-Dussoix 1969 \\
\hline \multicolumn{3}{|l|}{ Plasmids } \\
\hline pRL1063a & Plasmid containing a Tn 5 with promoterless $l u x A B ; \mathrm{Km}^{\mathrm{r}}$. & Wolk et al. 1991 \\
\hline pMP5406 & $\begin{array}{l}\text { pRL1063a derivative recovered from chromosomal DNA } \\
\text { of PCL1454 after digestion with EcoRI. }\end{array}$ & This study \\
\hline
\end{tabular}


mented with kanamycin or carbenicillin in final concentrations of 50 and $100 \mu \mathrm{g}$ per $\mathrm{ml}$, respectively. For the isolation of total rhizosphere microbial populations, TSA medium (Difco Laboratories) supplemented with $50 \mu \mathrm{g}$ of cycloheximide per ml was used.

For growth on naphthalene as the sole carbon source, SSM was modified by replacing succinate with naphthalene (Sigma, St. Louis, MO, U.S.A.), resulting in SNM. Naphthalene was added as crystals to liquid medium or placed in the lid of a petri dish when bacteria were grown on solidified medium.

Spontaneous rifampin-resistant derivatives of PCL1444 were generated by plating $0.1 \mathrm{ml}$ of an overnight culture on $\mathrm{KB}$ medium containing $200 \mu \mathrm{g}$ of rifampin per ml. Spontaneous resistant colonies were collected as a mixture. A suspension of approximately $10^{8} \mathrm{CFU} / \mathrm{ml}$ was used as an inoculant for grass seedlings. Plants were grown for 7 days in the gnotobiotic system, with quartz sand, as described below. After isolation of the bacteria from the root tips, the procedure to isolate rhizosphere-competent, rifampin-resistant mutants was repeated twice. Rifampin-resistant bacteria that were able to reach the root tip after three cycles were purified, and one of these isolates was chosen for subsequent experiments. The rationale of this procedure was to make sure that the rifampin resistance had no negative influence on the root tip colonizing ability of the strain.

To measure generation times, cultures were inoculated with approximately $10^{5} \mathrm{CFU} / \mathrm{ml}$, and growth in the respective medium was followed, in time, by plating dilutions on $\mathrm{KB}$ plates or by measuring the optical density at $620 \mathrm{~nm}$.

SNM containing $0.025 \mathrm{mg}$ of naphthalene per ml was used to study naphthalene degradation in liquid culture. Samples were taken each hour, extracted with 2 volumes of hexane (Merck, Darmstadt, Germany), shaken vigorously for $35 \mathrm{~min}$, and phases were allowed to separate. From each sample, $1 \mu \mathrm{l}$ of the hexane fraction was analyzed with gas liquid chromatography (GLC).

\section{Strain identification with PCR and sequencing of $16 S$ ribosomal DNA.}

In order to obtain the sequence of the $16 \mathrm{~S}$ ribosomal DNA, colony PCR was performed on strain PCL1444 with PCR primers oMP503 (GCTACCTTGTTACGACTTCGTCCC) and oMP504 (GCTCAGATTGAACGCTGGCCCG). A single colony was suspended in $20 \mu \mathrm{l}$ of sterile water. Subsequently, $1.0 \mathrm{ml}$ of $0.05 \mathrm{M} \mathrm{NaOH}-0.25 \%$ sodium dodecyl sulfate solution was added, and the mixture was incubated at $95^{\circ} \mathrm{C}$ for $15 \mathrm{~min}$. Ten microliters of a 10 -fold dilution of this suspension in sterile water was used as a template in a PCR reaction, with a hot start for $120 \mathrm{~s}$ at $95^{\circ} \mathrm{C}$, followed by 10 cycles consisting of $40 \mathrm{~s}$ at $94^{\circ} \mathrm{C}, 60 \mathrm{~s}$ at a decreasing temperature gradient of $1^{\circ} \mathrm{C}$ per cycle (starting from $60^{\circ} \mathrm{C}$ ), $120 \mathrm{~s}$ at $72^{\circ} \mathrm{C}$, and a subsequent 25 cycles consisting of $40 \mathrm{~s}$ at $94^{\circ} \mathrm{C}, 60 \mathrm{~s}$ at $50^{\circ} \mathrm{C}, 120 \mathrm{~s}$ at $72^{\circ} \mathrm{C}$, and a final extension of $72^{\circ} \mathrm{C}$ for $120 \mathrm{~s}$. The resulting PCR fragment was purified with the QIAquick PCR Purification Kit 50 (Westburg, Leusden, The Netherlands) and directly used for sequencing (Baseclear, Leiden, The Netherlands). DNAman software was used to analyze the sequence (Lynnon Biosoft, Quebec, Canada). Homology studies were carried out with the NCBI GenBank BLAST program (Altschul et al. 1997).
Isolation of microbes from roots from PAH-polluted soil.

Tauw Milieu (Deventer, The Netherlands) provided vegetation with adhering rhizosphere soil and bulk soil from a PAHpolluted site. Roots and adhering rhizosphere soil were shaken vigorously in $200 \mathrm{ml}$ of sterile phosphate buffered saline (PBS) for $2 \mathrm{~h}$. A sample was diluted and plated on 20 -fold diluted solidified TSA-cycloheximide and incubated at $28^{\circ} \mathrm{C}$. Subsequently, all colonies were scraped together from the plate, and this mixture was used to inoculate $100 \mathrm{ml}$ of SNM medium. After overnight growth under vigorous shaking at $28^{\circ} \mathrm{C}$, a 1-ml sample of this culture was taken, and the cells were washed with PBS. These bacteria were used to inoculate germinated sterile seedlings of Barmultra for colonization studies, as described below.

\section{Plants and plant growth conditions.}

The following grass cultivars were obtained from Barenbrug Research: L. perenne cvs. Bardessa and Barpolo, Barmultra, Festuca arundinacea cv. Barcel, Festuca rubra trichofylla cv. Barcrown, Dactylis glomerata cv. Baraula, and Koeleria macrantha cv. Barkoel. Plants were grown in climate-controlled growth chambers, with $16 \mathrm{~h}$ of daylight at $18^{\circ} \mathrm{C}$, in one of the following soil types: i) PAH-polluted soil used in the described studies, provided by Tauw Milieu and derived from a heavily PAH-polluted site in The Netherlands; ii) quartz sand (Wessem Filterzand, Wessem, The Netherlands) moistened with $10 \%$ (vol/wt) PNS, also referred to as quartz sand-PNS, was used for colonization assays in a gnotobiotic system, as described by Simons et al. (1996).; iii) quartz sand-naphthalene, identical to the sand used in the gnotobiotic system described above except that the PNS was saturated with approximately $0.03 \mathrm{mg}$ of naphthalene per $\mathrm{ml}$ (naphthalene crystals were removed by filtration); and iv) potting soil (Holland Potgrond, Poeldijk, The Netherlands), which was moistened with $10 \%$ (vol/wt) water before use. Potting soil-naphthalene consists of the same soil but moistened with water that was saturated with naphthalene.

To determine naphthalene degradation resulting from the presence of plants with or without bacteria, two systems, designated as "closed" and "two-layer," were used. The closed system was constructed with glass tubes $15 \mathrm{~cm}$ in height and $1.5 \mathrm{~cm}$ in diameter and filled with $15 \mathrm{~g}$ of quartz sand moistened with $10 \%$ (vol/wt) PNS, through which $3 \mathrm{mg}$ of naphthalene (300 $\mu \mathrm{l}$ of a $10 \mathrm{mg}$ per $\mathrm{ml}$ of stock solution in dichloromethane; Mallinckrodt Baker, Deventer, The Netherlands) was mixed. After evaporation of the dichloromethane, the system was sealed with a Viton stopper to prevent naphthalene leakage. The two-layer system was prepared to test naphthalene degradation as a result of the penetration of plant roots through a layer impermeable to bacteria. Glass tubes were filled with $5 \mathrm{~g}$ of quartz sand moistened with 10\% PNS, through which $3 \mathrm{mg}$ of naphthalene $(300 \mu \mathrm{l}$ of a $10 \mathrm{mg}$ per $\mathrm{ml}$ of stock solution in dichloromethane) was mixed. After evaporation of the dichloromethane, a sterile $1.8 \%$ water-agar layer (approximately $5 \mathrm{~mm}$ thick) was poured on top of the sand layer. After solidification, a second layer of $10 \mathrm{~g}$ of sand-PNS, without naphthalene, was added on top of the agar layer.

Naphthalene degradation in real soil was tested with reconstituted naphthalene-polluted soil. This soil is derived from the same site as the PAH-polluted soil described above, although naphthalene was not present anymore as a result of 
evaporation or degradation, as judged from GLC analysis. The bacterial background in this soil is approximately $10^{9} \mathrm{CFU} / \mathrm{g}$, which was determined by colony plating. This soil was used to identically construct the two-layer system as described previously for the quartz sand, with $3 \mathrm{mg}$ of naphthalene added to the lower layer.

\section{Evaluation of plant root systems.}

To determine root length and branching of the various cultivars, the root systems were inspected after 12 days of growth in PAH-polluted soil. The length of the main root of 10 plants of each cultivar was measured. Branching was evaluated by visual inspection. The number of bacteria that can be carried by the root systems was determined in colonization experiments and performed as described below except that, instead of the root tips, the entire root system was isolated.

\section{Root tip colonization after seedling inoculation.}

Sterilized germinated seedlings were soaked in a bacterial suspension of $108 \mathrm{CFU} / \mathrm{ml}$ or, in the case of competition assays, in a 1:1 mixture of cells of two strains and planted in the gnotobiotic system, as described by Simons et al. (1996). Approximately $5 \times 105$ bacteria became attached to one grass seedling. After plant growth for 7 days, the roots were approximately $10 \mathrm{~cm}$ in length. To estimate root tip colonization, the root tip $(1 \mathrm{~cm})$, with adhering rhizosphere sand, was isolated and shaken vigorously for $15 \mathrm{~min}$ in PBS to remove the bacteria. Dilutions of the bacterial suspensions were plated on KB medium, supplemented with antibiotics (when appropriate), and the plates incubated at $28^{\circ} \mathrm{C}$. All colonization experiments were performed in $10-$ fold. The average number of bacteria and the standard deviation were calculated. The nonparametric WilcoxonMann-Whitney test (Sokal and Rohlf 1981) for mixed inocula was used to perform statistics.

\section{Stability of naphthalene-degrading ability.}

The stability of the naphthalene-degrading ability of isolate PCL1444 was tested after serial dilution and subsequent growth in liquid $\mathrm{KB}$ medium and after seedling inoculation and plant growth for 8 days in the gnotobiotic system in the absence of naphthalene. In the first case, cells were diluted 1:1000 into fresh $\mathrm{KB}$ medium every $24 \mathrm{~h}$ until growth had occurred for approximately 100 generations. A sample from the culture was diluted and plated on KB medium. One hundred colonies were tested for growth on SNM plates at $28^{\circ} \mathrm{C}$. After seedling inoculation and subsequent plant growth in the gnotobiotic system, bacteria were isolated from the root tips (Simons et al. 1996) and plated on KB medium. Subsequently, 100 colonies from KB plates were tested for growth on SNM plates at $28^{\circ} \mathrm{C}$.

\section{Determination of the survival and proliferation of strain PCL1444, with and without plants.}

To determine the influence of the plant on the survival or growth of strain PCL1444, in sand or soil, strain PCL1444 was inoculated on grass seedlings as well as in soil without seedlings, in plant tubes containing $15 \mathrm{~g}$ of PAH-polluted soil, potting soil, and potting soil-naphthalene. Seedlings were soaked in a suspension of $10^{8} \mathrm{CFU} / \mathrm{ml}$ of the rifampin-resistant derivative of strain PCL1444, and two seedlings were placed in each plant tube. In the control without seedlings, $10 \mu \mathrm{l}$ of the bacterial suspension, which corresponds with the volume present on two seedlings, was pipetted into the soil at the position where seedlings would have been planted. Plants and bacteria were grown for 8 days. To isolate the bacteria from the soil, plants were removed from the soil and shaken separately in $1 \mathrm{ml}$ of PBS, as described previously. PBS $(10 \mathrm{ml})$ was added to the soil in the tubes, which were closed with Viton stoppers, and subsequently shaken for $1 \mathrm{~h}$. Dilutions were plated on $\mathrm{KB}$ plates supplemented with rifampin, to select for strain PCL1444, and with $50 \mu \mathrm{g}$ of cycloheximide per $\mathrm{ml}$, to prevent the growth of fungi. In order to determine the background bacterial activity in potting soil and PAH-polluted soil, some samples also were plated on KB plates without antibiotics. All experiments were performed with 10 tubes.

\section{Generation and isolation}

of a naphthalene degradation-defective mutant.

Transposon mutants of Pseudomonas spp. were generated by a triparental mating with $E$. coli strains containing plasmid pRL1063a, which harbors a promoterless Tn5-luxAB transposon (Wolk et al. 1991) and helper plasmid pRK2013 (Ditta et al. 1980). Mutants defective in naphthalene degradation were isolated after screening for the inability to grow on solidified SNM. To recover the regions flanking the site in which the Tn5-luxAB is inserted, chromosomal DNA of the mutant was digested with EcoRI. Recirculation of the Tn5-luxAB with the flanking chromosomal DNA was performed by ligation of the digested chromosomal DNA. Nucleotide sequencing of the flanking regions, starting from the $\operatorname{Tn} 5-\operatorname{lux} A B$ borders, was performed by BaseClear (Leiden, The Netherlands), with primers homologous to the left border (oMP407; 5'-TACTAGATTCAATGCTATCAATGAG-3') and the right border (oMP408; 5'-AGGAGGTCACATGGAATATCAGAT-3'), respectively. All general DNA techniques were performed as described by Sambrook et al. (1989). DNA sequences were analyzed with DNAman software and compared with the DNA databank through the NCBI BLAST search program (Altschul et al. 1997).

\section{Analysis of naphthalene degradation after seedling inoculation.}

Barmultra seedlings were inoculated by soaking them in a suspension $\left(10^{8} \mathrm{CFU} / \mathrm{ml}\right)$ of isolate PCL1444 or PCL1454 for $15 \mathrm{~min}$. Two inoculated seedlings were planted in each tube of the closed or two-layer system. For controls without plants, $10 \mu \mathrm{l}$ of the PCL1444 inoculation mix, corresponding to $10^{6} \mathrm{CFU}$, was pipetted into the sand at the position where seedlings normally would have been planted. Extractions were performed by adding $10 \mathrm{ml}$ of hexane to both layers of the plant tubes, which were closed again with the Viton stopper to prevent evaporation of hexane and naphthalene. After shaking for $24 \mathrm{~h}$, samples of $1.0 \mu \mathrm{l}$ were analyzed with the use of GLC with a GC3350 chromatograph (Varian Analytical Instruments, Houten, The Netherlands) equipped with a flame ionization detector (Packard 9200; NEC Computers, Kassel, Germany) with nitrogen as the carrier gas. The column used for PAH analysis was a J\&W DB5, with a capillary of $30 \mathrm{~m}$ in length, $0.31-\mathrm{mm}$ inside diameter, and $0.25 \mu \mathrm{m}$ of film (Varian Analytical Instruments). 


\section{ACKNOWLEDGMENTS}

We thank K. Eijkemans for technical assistance. I. Kuiper was supported by a grant from the Earth and Life Sciences Council NWO and the Technology Foundation STW, project GBI 55.3868 (73-95).

\section{LITERATURE CITED}

Altschul, S. E., Madden, T. L., Schaffer, A. A., Zhang, J., Zhang, Z., Miller, W., and Lipman, D. J. 1997. Gapped BLAST and PSI-BLAST: A new generation of protein database search programs. Nucleic Acids Res. 25:3389-3402.

Anderson, T. A., Guthrie, E. A., and Walton, B. T. 1993. Bioremediation in the rhizosphere. Environ. Sci. Technol. 27:2630-2636.

Aprill, W., and Sims, R. C. 1990. Evaluation of the use of prairie grasses for stimulating polycyclic aromatic hydrocarbon treatment in soil. Chemosphere 20:253-265.

Bodelier, P. L. E., Roslev, P., Henckel, T., and Frenzel, P. 2000. Stimulation by ammonium-based fertilizers of methane oxidation in soil around rice roots. Nature 403:421-424.

Boyer, H. W., and Roulland-Dussoix, D. 1969. A complementation analysis of the restriction and modification of DNA in Escherichia coli. J. Mol. Biol. 41:459-472

Brazil, G. M., Kenefick, L., Callanan, M., Haro, A., de Lorenzo, V., Dowling, D. N., and O'Gara, F. 1995. Construction of a rhizosphere Pseudomonad with potential to degrade polychlorinated biphenyls and detection of $b p h$ gene expression in the rhizosphere. Appl. Environ. Microbiol. 61:1946-1952.

Cerniglia, C. E. 1993. Biodegradation of polycyclic aromatic hydrocarbons. Curr. Opin. Biotechnol. 4:331-338.

de Mot, R., and Vanderleyden, J. 1991. Purification of a root-adhesive outer membrane protein of root-colonizing Pseudomonas fluorescens. FEMS Microbiol. Lett. 81:323-328.

Dekkers, L. C., van der Bij, A. J., Mulders, I. H. M., Phoelich, C. C., Wentwoord, R. A. R., Glandorf, D. C. M., Wijffelman, C. A., and Lugtenberg, B. J. J. 1998. Role of the O-antigen of lipopolysaccharide, and possible roles of growth rate and NADH:ubiquinone oxidoreductase (пио) in competitive tomato root-tip colonization by Pseudomonas fluorescens WCS365. Mol. Plant-Microbe Interact. 11: 763-771.

Denome, S. A., Stanley, D. C., Olson, E. S., and Young, K. D. 1993. Metabolism of dibenzothiophene and naphthalene in Pseudomonas strains: Complete DNA sequence of an upper naphthalene catabolic pathway. J. Bacteriol. 175:6890-6901.

Ditta, G., Stanfield, S., Corbin, D., and Helsinki, D. R. 1980. Broad host range DNA cloning system for gram-negative bacteria: Construction of a gene bank of Rhizobium meliloti. Proc. Natl. Acad. Sci. USA 77: 7347-7351.

Erickson, L. E. 1997. An overview of research on the beneficial effects of vegetation in contaminated soil. Ann. NY Acad. Sci. 829:30-35.

Geels, F. P., and Schippers, B. 1983. Selection of antagonistic fluorescent Pseudomonas spp. and their root colonization and persistence following treatment of seed potatoes. Phytopathol. Z. 108:193-206.

Goldstein, R. M., Mallory, L. M., and Alexander, M. 1985. Reasons for possible failure of inoculation to enhance biodegradation. Appl. Environ. Microbiol. 50:977-983.

Gregory, P. J., and Atwell, B. J. 1991. The fate of carbon in pulselabelled crops of barley and wheat. Plant Soil 136:205-213.

Grosser, R. J., Warshawsky, D., and Vestal, J. R. 1991. Indigenous and enhanced mineralization of pyrene, benzo(a)pyrene, and carbazole in soils. Appl. Environ. Microbiol. 57:3462-3469.

Hiltner, L. 1904. Uber neue Erfahrungen und Probleme auf dem Gebiet der Bodenbakteriologie. Arb. Dtsch. Landwirt. Ges. Berl. 98:59-78.

Keith, H., Oades, J. M., and Martin, J. K. 1986. Input of carbon to soil from wheat plants. Soil Biol. Biochem. 18:445-449.

King, E. O., Ward, M. K., and Raney, D. E. 1954. Two simple media for the demonstration of pyocyanin and fluorescin. J. Lab. Clin. Med. 44:301-307.

King, G. M. 1994. Association of methanotrophs with the roots and rhizomes of aquatic vegetation. Appl. Environ. Microbiol. 60:3220-3227.

King, J. M. H., DiGrazia, P. M., Applegate, B., Larimer, F., and Sayler, G. S. 1990. Rapid, sensitive bioluminescent reporter technology for naphthalene exposure and biodegradation. Science 249:778-781.
Koster, M., Van de Vossenberg, J., and Weisbeek, P. J. 1993. Identification and characterization of the pupB gene encoding an inducible ferricpseudobactin receptor of Pseudomonas putida WCS358. Mol. Microbiol. 8:591-601.

Leahy, J. G., and Colwell, R. R. 1990. Microbial degradation of hydrocarbons in the environment. Microbiol. Rev. 54:305-315.

Liste, H.-H., and Alexander, M. 2000. Plant-promoted pyrene degradation in soil. Chemosphere 40:7-10.

Long, G. M. 1993. Clean up hydrocarbon contamination effectively. Chem. Eng. Prog. 5:58-67.

Lugtenberg, B. J. J., Dekkers, L. C., Bansraj, M., Bloemberg, G. V., Camacho, M., Chin-A-Woeng, T. F. C., van den Hondel, K. Kravchenko, L., Kuiper, I., Lagopodi, A., Mulders, I., Phoelich, C., Ram, A., Tikhonovich, I., Tuinman, S., Wijffelman, C., and Wijfjes, A. 1999. Pseudomonas genes and traits involved in tomato root colonization. Pages 324-330 in: Biology of Plant-Microbe Interactions. P. J. G. M. de Wit, T. Bisseling, and W. J. Stiekema, eds. International Society for Molecular Plant-Microbe Interactions, St. Paul, MN, U.S.A.

Lynch, J. M., and Whipps, J. M. 1990. Substrate flow in the rhizosphere. Plant Soil 129:1-10.

Martin, J. K. 1974. Comparison of agar media for counts of viable soil bacteria. Soil Biol. Biochem. 7:401-402.

Meyer, J. M., and Abdallah, M. A. 1978. The fluorescent pigment of Pseudomonas fluorescens: Biosynthesis, purification and physicochemical properties. J. Gen. Microbiol. 107:319-328.

Morgan, P., and Watkinson, R. J. 1989. Hydrocarbon degradation in soil and methods for soil biotreatment. CRC Crit. Rev. Biotech. 8:305333

Nichols, T. D., Wolf, D. C., Rogers, H. B., Beyrouty, C. A., and Reynolds, C. M. 1997. Rhizosphere microbial populations in contaminated soils. Water Air Soil Pollut. 95:165-178.

Radwan, S., Sorkhoh, N., and El-Nemr, I. 1995. Oil biodegradation around roots. Nature 376:302.

Ramadan, M. A., Tayeb, O. M., and Alexander, M. 1990. Inoculation size as a factor limiting success of inoculation for biodegradation. Appl. Environ. Microbiol. 56:1392-1396.

Sambrook, J., Fritsch, E. F., and Maniatis, T. A. 1989. Molecular Cloning: A Laboratory Manual, 2nd ed. Cold Spring Harbor Laboratory, Cold Spring Harbor, NY, U.S.A.

Schippers, B., Scheffer, R. J., Lugtenberg, B. J. J., and Weisbeek, P. J. 1995. Biocoating of seeds with plant growth-promoting rhizobacteria to improve plant establishment. Outlook Agric. 25:179-185.

Schwab, A. P., Banks, M. K., and Arunachalam, M. 1995. Biodegradation of polycyclic aromatic hydrocarbons in rhizosphere soil. Pages 23-29 in: Bioremediation of Recalcitrant Organics. R. E. Hinchee, D. B. Anderson, and R. E. Hoeppel, eds. Battelle Memorial Institute, Columbus, OH, U.S.A.

Simons, M., van der Bij, A. J., Brand, I., de Weger, L. A., Wijffelman, C. A., and Lugtenberg, B. J. J. 1996. Gnotobiotic system for studying rhizosphere colonization by plant growth-promoting Pseudomonas bacteria. Mol. Plant-Microbe Interact. 9:600-607.

Sokal, R. R., and Rohlf, F. J. 1981. Biometry. Freeman Publications, San Francisco.

Timmis, K. N., and Pieper, D. H. 1999. Bacteria designed for bioremediation. Tibtech 17:201-204.

Trofymow, J. A., Coleman, D. C., and Cambardella, C. 1987. Rates of rhizodeposition and ammonium depletion in the rhizosphere of axenic oat roots. Plant Soil 97:333-344.

van der Bij, A. J., de Weger, L. A., Tucker, W. T., and Lugtenberg, B. J. J. 1996. Plasmid Stability in Pseudomonas fluorescens in the rhizosphere. Appl. Environ. Microbiol. 62:1076-1080.

Van Elsas, J. D., Trevors, J. T., and Starodub, M. E. 1988. Bacterial conjugation between pseudomonads in the rhizosphere of wheat. FEMS Microbiol. Ecol. 53:299-306.

Walton, B. T., and Anderson, T. A. 1990. Microbial degradation of trichloroethylene in the rhizosphere: Potential application to biological remediation of waste sites. Appl. Environ. Microbiol. 56:1012-1016.

Wolk, C. P., Cai, Y., and Panoff, J.-M. 1991. Use of a transposon with luciferase as a reporter to identify environmentally responsive genes in cyanobacterium. Proc. Natl. Acad. Sci. USA 88:5355-5359.

Yee, D. C., Maynard, J. A., and Wood, T. K. 1998. Rhizoremediation of trichloroethylene by a recombinant, root-colonizing Pseudomonas fluorescens strain expressing toluene ortho-monooxygenase constitutively. Appl. Environ. Microbiol. 64:112-118. 